\title{
Benign Endikasyonlarda Laparoskopik ve Abdominal Histerektomi
}

\author{
Comparison of Laparoscopic and Abdominal Hysterectomy for Benign Diseases
}

\section{Emine Öztürk ${ }^{1}$, Hakan Güraslan ${ }^{2}$, Keziban Doğan ${ }^{2}$, Mehmet Baki Şentürk ${ }^{3}$ Birgül Güraslan ${ }^{2}$, Nadire Sevda İdil ${ }^{2}$, Levent Yaşar ${ }^{2}$}

\begin{abstract}
1. Bahçelievler Devlet Hastanesi, Kadın Hastalıkları ve Doğum Kliniği, Istanbul, Türkiye
2. Bakırköy Dr Sadi Konuk Eğitim ve Araştırma Hastanesi, Kadın Hastalıkları ve Doğum Kliniği, İstanbul, Türkiye 3. Zeynep Kamil Kadın ve Çocuk Hastalıkları EAH, Kadın Hastalıkları ve Doğum Kliniği, İstanbul, Türkiye
\end{abstract}

\section{$\ddot{O Z Z E T}$}

Amaç: Bu çalışmanın amacı benign endikasyonlarla yapılan histerektomilerde laparoskopik yaklaşım ile abdominal yaklaşımın intraoperatif ve kısa dönem postoperatif komplikasyonlarını karşılaştırmak.

Gereç ve Yöntem: Bu retrospektif kohort çalışmasında Ocak 2011-Aralı 2013 tarihleri arasinda benign nedenlerle total abdominal ve laparoskopik histerektomi yapllan 253 hastanin orijinal dosyalart ve ameliyat raporlart analiz edildi. İki ayrı histerektomi yaklaşımı operasyon süresi, kan kaybı, majör komplikasyonlar ve hastanede yatış süresi açısından karşılaştırıldı.

Bulgular: Toplam 253 hastanin 151 tanesine (\%60) abdominal, 102 (\%40) tanesine laparoskopik histerektomi yapılmıştır. Operasyon süresi laparoskopik histerektomi grubunda anlaml olarak daha uzun saptand ( $p=$ 0,001). Majör komplikasyonlar açısından laparoskopik histerektomi ile abdominal histerektomi arasinda fark saptanmadı $(p=0,560)$. Postoperatif hemoglobin düşüşü TAH grubunda daha fazlaydl $(p=0,031)$. Hastanede yatış süresi laparoskopik histerektomi grubunda anlaml olarak daha kısaydı (p =0,004). Laparoskopik histerektomi de laparotomiye dönme oranı $\% 12$ olarak saptandı.

Sonuç: Laparoskopik histerektomi abdominal histerektomiye oranla kisa iyileşme periyodu, daha az postoperatif rahatsızlık, daha iyi kozmetik sonuçlar gibi birçok avantaja sahiptir. Her iki yaklaşımdaki majör komplikasyon oranı benzerdir. Vajinal histerektominin uygun olmadı̆̆ hastalarda laparoskopik yaklaşım abdominal yaklaşıma tercih edilmelidir.

Anahtar Kelimeler: kan kaybl; endoskopi; jinekolojik cerrahi; histerektomi; laparoskopi

\section{İletişim Bilgileri:}

Sorumlu Yazar: Hakan Güraslan

Yazışma Adresi: Dr Sadi Konuk EAH, Kadın Hast. ve Doğ. KI. Tevfik Sağlam Cad. No:11 Zuhuratbaba, Bakırköy 34147, İstanbul E-posta: guraslanhakan@gmail.com

Tel: +90 (532) 2371003

Makalenin Geliş Tarihi: 06.09.2015

Makalenin Kabul Tarihi: 20.03.2016

DOI: http://dx.doi.org/10.16948/zktb.40306

\section{ABSTRACT}

Objective: The aim of this study was to compare the intraoperative and short term postoperative complications between the abdominal and laparoscopic hysterectomies for women with benign disease.

Material and Method: In this retrospective cohort study, we analyzed the files of the 253 patients who underwent total abdominal or laparoscopic hysterectomy for benign conditions in our clinic between January 2011 and December 2013. The operating time, blood loss, the major complication rate and the duration of hospital stay were compared between the abdominal and the laparoscopic hysterectomy groups respectively.

Results: Among the total of the 253 patients, hysterectomy was performed abdominally for 151 (60\%) patients and laparoscopically for the 102 (40\%) patients. The operating time was found to be significantly longer for the laparoscopic approach $(p=0.001)$. No statistically significant difference was found between the groups for the major complication rate $(p=0.560)$. Postoperative decline for hemoglobin levels in the abdominal hysterectomy group was higher than in the laparoscopic group $(p=0.031)$. The duration of hospital stay was found to be shorter in the laparoscopic group $(p=0.004)$. The conversion rate to open surgery was $12 \%$.

Conclusion: Laparoscopic hysterectomy has more advantages than abdominal hysterectomy when compared for time needed for postoperative recovery, abdominal discomfort after surgery and cosmetically results. The major complication rates were similar for the two approaches. When vaginal approach is not appropriate for the patient, laparoscopic hysterectomy should be considered as the first option for the surgery.

Keywords: blood loss; endoscopy; gynecologic surgery; hysterectomy; laparoscopy 


\section{GİRIŞ}

Laparoskopik histerektomi k1sa hospitalizasyon, daha az intraoperatif kan kaybı, daha az postoperatif ağrı, hızlı iyileşme ve daha düşük infeksiyon oranları sunar, ancak uygulanma oranları halen abdominal histerektominin çok altındadır [1]. Amerika Birleşik Devletlerinde 2010 y1lında histerektomilerin \% 54.2 si abdominal yolla yapilırken sadece $\% 8.6$ si laparoskopik yapılmıştır [2]. Ülkemizde de durum farklı değildir. Laparoskopik cerrahide önde gelen merkezlerimizde bile abdominal histerektomi oranları laproskopik histerektominin çok üstündedir [3]. Bu laparoskopik yaklaşımda başta üriner olmak üzere majör komplikasyon oranın daha yüksek olması ve laparoskopik histerektominin öğrenme eğrisinin daha uzun olması ile açıklanabilir.

Benign endikasyonlarda histerektomi için en uygun cerrahi yaklaşımın değerlerledirildiği 2015 Cochrane derlemesinin sonuçlarına göre vaginal histerektomi abdominal ve laparoskopik yaklaşımdan üstündür ve ilk tercih olmalıdır. Vajinal histerektominin uygun olmadığ 1 hastalarda abdominal histerektomiden kaçınmak için laparoskopik yaklaşım önerilebilir, ancak laparoskopik histerektominin daha fazla üriner yol komplikasyonları ile ilişkili olduğu dikkate alınmalıdır [4]. Metaanalizlerin aksine deneyimli ellerde laparoskopik histerektominin majör komplikasyon oranını arttırmadığını rapor eden geniş serili çalışmalar da vardır $[5,6]$.

Biz bu makalede kliniğimizde benign endikasyonlarla yapilan 253 total abdominal ve laparoskopik histerektomi olgusunu sunuyoruz. Bu çalışmanın amacı abdominal ve laparoskopik histerektomide komplikasyon oranlarını değerlendirmektir.

\section{GEREÇ ve YÖNTEM}

Ocak 2011 - Aralık 2013 tarihleri arasında, Bakırköy Dr Sadi Konuk Eğitim ve Araştırma Hastanesi Kadın Hastalıkları ve Doğum Kliniginde histerektomi yapılan 437 hasta retrospektif olarak gözden geçirildi. Malignite nedeniyle histerektomi yapılan 112, postpartum kanama nedeniyle sezeryan histerektomi yapılan 2, supraservikal ve laparoskopik asiste vajinal histerektomi yapılan 47 hasta ile kayıtları eksik olan 23 hasta çalışma dışı bırakıldı.

Tüm hastaların orjinal dosyaları, anestezi kayıtları ve operasyon notları analiz edildi. Yaş, kilo, boy, parite, menapozal durum, sezeryan ve diğer abdominal cerrahi öyküsü, histerektomi endikasyonu kayıt edildi.
Primer sonuçlar operasyon süresi, major komplikasyon oran1, postoperatif hemoglobin düşüş oranı ve hastanede yatış süresi olarak belirlendi. İntraoperatif tahmini kan kaybını belirten objektif bir ölçüm yapılmamıștı. Bu nedenle kanama paterni değerlendirmesi için operasyon sonrası hemoglobindeki düşüş dikkate alındı.

Operasyon süresi ilk cilt insizyonuyla insizyonun tamamen kapatılması arasındaki süre olarak tanımlandı. Hemoglobin değerleri için operasyondan 12 saat önce ve 24 saat sonraki ölçümler kaydedildi. Operasyon tarihinden taburcu tarihine kadar geçen süre hastanede kalış süresi olarak kabul edildi. Tüm hastalara operasyondan 1 saat önce, Sefazolin 1 gr İV olarak uygulanmış ve postoperatif 12.saatte aynı doz tekrarlanmıştı. Tromboemboli profilaksisi için operasyondan 8 saat önce Enoxaparin $0.4 \mathrm{ml}$ S.C uygulandığ 1 ve yatış boyunca 24 saat arayla devam edildiği görüldü.

İstatistiksel analizler NCSS (Number Cruncher Statistical System) 2007 Statistical Software (Utah, USA) paket programı ile yapıld1. Verilerin değerlendirilmesinde tanımlayıcı istatistiksel metotların (ortalama,standart sapma) yanı sıra ikili grupların karşılaştırmasında bağımsız t testi, operasyon öncesi ve operasyon sonrası değişkenlerin değerlendirilmesinde eşlendirilmiş $\mathrm{t}$ testi, normal dağılım göstermeyen parametrelerde Mann-Whitney U testi, nitel verilerin karşılaştırmalarında ki-kare ve uygun olduğu yerde Fisher gerçeklik testi kullanıldı. Anlamlilik $\mathrm{p}<0,01$ ve $\mathrm{p}<0,05$ düzeylerinde değerlendirildi.

Histerektomi Prosedürü: Kliniğimizde total laparoskopik histerektomi ve total abdominal histerektomi tekniği tüm hastalara aşağıda tanımlandığı gibi uygulanmaktadır.

TLH prosedürü: Batına umblikusun tam ortasından kapalı teknikle ve 90 derece açı ile girilip pnömoperitoneum oluşturulduktan sonra kamera için umblikustan $10 \mathrm{~mm}$ port $(10 \mathrm{~mm}$ trochar; Ethicon Endo-Surgery, Cincinnati, $\mathrm{OH}$, USA) girilir. İki tanesi spina iliaka anterior superiorun $2 \mathrm{~cm}$ medialine, bir tanesi suprapubik olmak üzere üç adet $5 \mathrm{~mm}$ port (Ethicon Endo-Surgery) direkt görüş altında girilir. Uterus manipülasyonu için Clermont-Ferrand uterin manüplatör (Karl Storz, Tuttlingen, Germany) yerleştirilir.

Operasyona $5 \mathrm{~mm}$ harmonic scalpel (Ethicon Endo-Surgery) ile ligamentum rotundumlar yakılıp kesilerek başlanır. Ligamentum latumda pencere açılarak üreter uzaklaştırıldıktan sonra, ya da üreterler sadece periton dışından 
gözlenerek EnSeal ile (Ethicon Endo-Surgery) infundibulopelvik ligament ya da utero-ovarian ligament koagüle edilerek kesilir. Broad ligamentin arka yaprağ1 uterosakral ligamente doğru disseke edilir. Uterus önünde periton harmonic scalpel ya da bipolar koter ve makas ile açılarak mesane serviks ön yüzünden vajene doğru uzaklaştırılır. Uterin arterlerler EnSeal ile koagüle edildip kesildikten sonra, servikovajinal bileșkeden harmonic scalpel ile kesilerek piyes çıkarılır. Vajen kafı laparoskopik olarak V-loc ${ }^{\mathrm{TM}}$ (Covidien, Dublin, Ireland) sütür ile kapatilır.

$\underline{T A H}$ prosedürü:: Operasyona uterusun büyüklügüne göre simfiz üstünden transvers ya da median insizyonla batına girilerek başlanır. Abdominal kavite eksplore edildikten sonra ligamentum rotundumlar kesilip bağlanır. Periton infundibulopelvik ligamente doğru açıldıktan sonra ya periton dişından ya da retroperitoneal alana girilerek bilateral üreterler belirlenir. Aynı şekilde ligamentum latumda pencere açılarak üreterler uzaklaştırılır. Uteroovaryan ya da infundibulopelvik ligamentler kesilip bağlanır.

Mesane uterus ön yüzünden uzaklaștırıldıktan sonra uterin arterler kesilip bağlanır. Önden ya da yandan vajene girilerek piyes çıkarıldiktan sonra vaginal cuff 1 numara absorbabl sütürle kontinü kapatılır.

\section{BULGULAR}

Çalışmaya 151 tanesi TAH, 102 tanesi TLH olmak üzere toplam 253 hasta kaydedildi. Hastaların ortalama yașı $49 \pm 7$ (34-89) ortalama vücut kitle indeksi $30 \pm 4$ (21-49) idi. Parite, preoperatif hemoglobin değeri, geçirilmiş sezeryan ve abdominal cerrahi öyküsü açısından gruplar arasında fark yoktu. TLH grubunda ortalama vücut kitle indeksi $(32 \pm 6) \mathrm{TAH}$ grubundan $(29 \pm 3)$ daha yüksekti $(\mathrm{p}<0.001)$. Ortalama yaş, ve postmenapozal hasta oranı da TLH grubunda anlamlı olarak daha yüksekti (p $<0.001$ ) (Tablo 1).

\begin{tabular}{|c|c|c|c|}
\hline & TAH $n=151$ & TLH $n=102$ & $p$ \\
\hline Yaş (y) & $47 \pm 4$ & $52 \pm 9$ & $<0.001^{* *}$ \\
\hline $\mathrm{BMI}(\mathrm{kg} / \mathrm{m} 2)$ & $29 \pm 3.2$ & $32 \pm 6.1$ & $<0,001^{* *}$ \\
\hline Menapoz durumu & $35(23.2 \%)$ & $64(62.7 \%)$ & $<0.001^{* *}$ \\
\hline Parite & $3 \pm 1.2$ & $2.9 \pm 1.9$ & 0.964 \\
\hline $\mathrm{c} / \mathrm{S}$ & $15(9.9 \%)$ & $9(8.8 \%)$ & 0.768 \\
\hline Abdominal cerrahi öyküsü & $15(9.9 \%)$ & $17(16.7 \%)$ & 0.114 \\
\hline
\end{tabular}

Histerektomi yapılan hastalarda iki grupta da en s1k endikasyon leiomyomdu (65\%). Ancak TAH grubunda leiomyoma oran $1(82 \%)$ TLH grubundan (40\%) fazlayken, endometrial hiperplazi, endometrial polip, servikal displazi ve adneksiyal kitle endikasyonları TLH grubunda daha siktı (Tablo 2).

Tablo 2: TLH ve TAH olgularında endikasyonlar.
\begin{tabular}{|c|c|c|c|c|}
\hline & $\begin{array}{c}\mathrm{TAH} \\
\mathrm{N}=151\end{array}$ & $\begin{array}{c}\mathrm{TLH} \\
\mathrm{N}=102\end{array}$ & $\begin{array}{c}\text { Total } \\
\mathrm{N}=253\end{array}$ & $p$ \\
\hline Leiomyoma & $\begin{array}{c}123 \\
(81.5 \%)\end{array}$ & $\begin{array}{c}41 \\
(40.2 \%)\end{array}$ & $\begin{array}{c}164 \\
(64.8 \%)\end{array}$ & $<0.001^{* *}$ \\
\hline Anormal uterin kanama & $\begin{array}{c}17 \\
(11.3 \%)\end{array}$ & $\begin{array}{c}15 \\
(14.7 \%)\end{array}$ & $\begin{array}{c}32 \\
(12.6 \%)\end{array}$ & 0.420 \\
\hline Endometrial hiperplazi & $\begin{array}{c}5 \\
(3.3 \%)\end{array}$ & $\begin{array}{c}25 \\
(24.5 \%)\end{array}$ & $\begin{array}{c}30 \\
(11.9 \%)\end{array}$ & $<0.001^{* *}$ \\
\hline Endometrial polip & $\begin{array}{c}4 \\
(3.9 \%)\end{array}$ & $\begin{array}{c}4 \\
(1.6 \%)\end{array}$ & $0.025^{*}$ \\
\hline Servikal displazi & $\begin{array}{c}5 \\
(4.9 \%)\end{array}$ & $\begin{array}{c}5 \\
(2 \%)\end{array}$ & $0.01^{* *}$ \\
\hline Kronik pelvik ağrı & $\begin{array}{c}2 \\
(1.3 \%)\end{array}$ & $\begin{array}{c}3 \\
(2.9 \%)\end{array}$ & $\begin{array}{c}5 \\
(2 \%)\end{array}$ & 0.651 \\
\hline Adneksiyal kitle & $\begin{array}{c}6 \\
(5.9 \%)\end{array}$ & $\begin{array}{c}6 \\
(2.4 \%)\end{array}$ & $0.004^{* *}$ \\
\hline Uterin prolapsus & $\begin{array}{c}1 \\
(2.6 \%)\end{array}$ & $\begin{array}{c}5 \\
(1 \%)\end{array}$ & 0.417 \\
\hline$p<0.05, * * p<0.01$ & $(2 \%)$ & $\begin{array}{c}2 \\
(0.8 \%)\end{array}$ & 0.162 \\
\hline
\end{tabular}

TAH grubunda ortalama operasyon süresi (118 dak, aralık 60-240), TLH grubundan (131 dak, aralık 75-235) daha kisa idi $(\mathrm{p}=0.001)$. Postoperatif 1. gün hemoglobin değerindeki düşüş TAH grubunda daha yüksekti $(\mathrm{p}=0.031)$. Ancak transfüzyon gereksinimi olan hasta say1s1 açısından TAH ( 22 hasta) ve TLH ( 9 hasta) grupları arasında fark yoktu $(\mathrm{p}=0.171)$. Hastanede yatış süresi TLH yapılan hastalarda anlamlı olarak daha kısaydı $(\mathrm{p}=0.004)$ (Tablo 3).

Tablo 3: TAH ve TLH olgularında operatif ve postoperatif bulgular.

\begin{tabular}{|l|l|l|l|}
\hline & \multicolumn{1}{|c|}{ TAH } & \multicolumn{1}{c|}{ TLH } & \multicolumn{1}{c|}{$p$} \\
\hline Operasyon süresi (dk) & $118 \pm 25$ & $131 \pm 31$ & $<0.001^{* *}$ \\
\hline Yatış süresi (gün) & $2.9 \pm 1.2$ & $2.5 \pm 1.3$ & $0.004^{* *}$ \\
\hline Preoperatif hb (g/dL) & $10.8 \pm 1.5$ & $11 \pm 1.5$ & 0.346 \\
\hline Postoperatif hb (g/dL) & $9.6 \pm 1.4$ & $10.2 \pm 1.5$ & $0.002^{* *}$ \\
\hline Postoperatif hb düşüşü (\%) & $9.8 \pm 8$ & $7.4 \pm 9.6$ & $0.031^{*}$ \\
\hline Uterus ağırlığı (g) & $409 \pm 360$ & $200 \pm 114$ & $<0.001^{* *}$ \\
\hline${ }^{*} p<0.05, \quad * * p<0.01$ & & &
\end{tabular}

TAH yapılan hastaların $6 \%$ sinda $(\mathrm{n}=9)$, TLH yapılanların $8 \%$ inde $(\mathrm{n}=8)$ majör komplikasyon olduğu görüldü $(\mathrm{p}=0.560)$. TLH grubundaki 8 majör komplikasyonun 5 tanesi çalışmamızın ilk yılına aitti. Üç tanesi TAH grubunda 3 tanesi TLH grubunda olmak üzere 6 hastada barsak yaralanması olmuştu. TLH grubundaki 1 barsak yaralanması Palmer noktasından batına giriş sırasında oluşmuş, mini 
laparotomi ile barsak segmenti dıșarı alınarak onarılmıș ve operasyona laparoskopik devam edilmişti. Diğer 2 barsak hasarından 1 tanesi laparoskopik olarak onarılırken koter hasarı nedeniyle oluştuğu düşünülen diğer barsak yaralanması operasyon sırasında farkedilememiş, bu hastaya operasyondan 4 gün sonra sigmoid perforasyon nedeniyle laparotomi yapılmıştı. TAH grubunda 3 yara yeri infeksiyonu ve 1 yara ayrılması görülürken, TLH grubunda yara yeri komplikasyonu yoktu. Ancak 2 vajinal kaf ayrilması ve 2 vajinal kaf kanamasi TLH yapılan hastalardaydı. Vajen cuf ayrilması olan 2 hastada erken cinsel ilișki öyküsü vardı. Bunlardan 1 tanesi tekrar sütüre edilirken, küçük bir ayrılma olan diğeri 10 günde spontan kapanmıştı. Toplam ürolojik komplikasyon oranı her iki grupta da \%3 olarak saptandı. Bunların 6 tanesi mesane yaralanması (4 ü TAH, 2 si TLH grubunda), 2 tanesi vezikovaginal fistüldü (1 TAH, $1 \mathrm{TLH}$ grubunda). Bu 6 vakada da yoğun adezyonlar mevcuttu. Mesane yaralanmalar1 intraoperatif onarılmış ve yaralanmanın büyüklügüune göre 8-10 gün bir Foley kateter konularak takip edilmişti. Bu hastalar komplikasyonsuz olarak iyileşirken, iki vezikovaginal fistül vakası da 2 ay sonda uygulaması ile spontan kapanmışt1. İki grupta da üreter yaralanması yoktu. Total komplikasyon oranları da gruplar arasında fark11 değildi $(\mathrm{p}=0.610)$ (Tablo 4).

\begin{tabular}{|c|c|c|c|}
\hline & $\begin{array}{c}\text { TAH } \\
n=151\end{array}$ & $\begin{array}{c}\text { TLH } \\
\mathrm{n}=102\end{array}$ & $p$ \\
\hline \multicolumn{4}{|l|}{ Majör komplikasyonlar } \\
\hline Mesane yaralanması & 4 & 2 & 1.0 \\
\hline Vezikovaginal fistül & 1 & 1 & 1.0 \\
\hline Barsak yaralanması & 3 & 3 & 0.688 \\
\hline İnsizyonal dehisens & 1 & & 1.0 \\
\hline Vaginal kaf dehisensi & & 2 & 0.162 \\
\hline \multicolumn{4}{|l|}{ Minör komplikasyonlar } \\
\hline Yara yeri infeksiyonu & 3 & & 0.275 \\
\hline Vaginal kaf kanaması & & 2 & 0.162 \\
\hline Total komplikasyonlar & 12 & 10 & 0.610 \\
\hline
\end{tabular}

TLH yapılan hastaların $\% 12$ sinde (12 hasta) laparotomiye dönüldüğ̈̈ görüldü. Bu hastaların morbid obez olan 4 tanesinde pnömoperitoneum ve trendelenburg pozisyonu sonras1 respiratuar problemler oluşmuş ve anestezinin önerisiyle laparotomiye geçilmişti. Kalan 8 hastanın 4 ünde yoğun adezyonlar, 3 ünde aşağ1 yerleşimli leiomyoma bağlı görüş azlığı ve 1 tanesinde kontrol edilemeyen kanama nedeniyle laparotomiye dönülmüștü.

\section{TARTIŞMA}

Çalışmamızın sonuçları total laparoskopik histerektominin total abdominal histerektomiye benzer komplikasyon oranlarıyla güvenle uygulanabilen bir cerrahi prosedür olduğunu göstermektedir.

Histerektominin laparoskopik yolla uygulanmasındaki temel kaygı bazı çalışmalarda $[7,8]$ rapor edilen artmış üriner sistem komplikasyon oranlarıdır. Bunlardan çok merkezli, iki paralel randomize çalıșmayı içeren eVALuate çalışmasında laparoskopik histerektominin abdominal histerektomiye kıyasla daha fazla majör komplikasyonla ve daha uzun operasyon süresiyle ilişkili olduğu rapor edilmiştir [7]. Bu çalışmada en belirgin komplikasyon farkları majör kanama ve üriner sistem yaralanmasıdır. Buna karşılık histerektominin laparoskopik yapılması daha az postoperatif ağrı, daha kısa hastanede kalıș süresi, hızlı iyileșme ve yaşam kalite göstergelerinde kısa dönemde hızlı düzelme sağlamıştır. Ancak eVAluate çalışması yüksek komplikasyon oranlarına yol açabilecek, laparoskopik histerektomi deneyimleri farkli 43 jinekolog içermektedir ve analizlerde cerrah deneyimi dikkate alınmadığı için eleştiri almıştır [9]. Benzer şekilde Aarts ve ark 2140 kadını içeren 13 randomize kontrollü çalışmayı değerlendirdikleri Cochrane derlemesinde laparoskopik histerektomi grubunda daha hizlı normal aktiviteye dönüş olsa da daha fazla üriner trakt yaralanması (OR 2.4, \%95 CI 1.2-4.8) olduğu sonucuna varmışlardır [4]. Ancak bu derlemede çalışmalar düşük kalite kanıtlar içermektedir. Laparoskopik histerektomide komplikasyon oranının abdominal yaklaşımdan farklı olmadığını rapor eden çalıșmalar da vardır. Donnez ve ark 3190 laparoskopik histerektomiyi abdominal ve vajinal yaklaşımla karşılaştırdıkları çalışmalarında deneyimli ellerde laparoskopik yaklaşımın majör komplikasyonlarda artışla ilişkili olmadığı sonucuna varmışlardır [6].

Bu çalışmada tüm laparoskopik histerektomiler yılda ortalama 200 laparoskopik histerektomi yapan, deneyimli bir ekip tarafından yapılmıştır ve majör komplikasyon oranı $\% 0.51$ bulunmuştur. Benzer şekilde Karaman ve ark nın rapor ettikleri 1120 laparoskopik asiste vaginal histerektomi ve laparoskopik histerektomide $\% 1$ major komplikasyon görülürken, üriner sistem komplikasyonu olmadığı rapor edilmiştir [5]. Bizim çalışmamızda laparoskopik histerektomi grubunda majör komplikasyon oranımız \%8 idi. Bu oran Donnez ve ark ile Karaman ve ark nın rapor ettiklerinden oldukça yüksek olsa da genel olarak literatürdeki diğer çalışmalarla [7, 10-12] uyumludur. 
Laparoskopik histerektomi yapılan hastalardaki ürolojik komplikasyon oranımız (\%3) diğer çalışmalarla [11, 13-15] karşılaştırılabilir düzeydeydir ve abdominal histerektomi yapılan hastalardan farklı değildir. Ayrıca majör komplikasyon oranlarımız da iki grupta benzerdir. Çalışma grubumuzda yara yeri komplikasyonları sadece abdominal histerektomi sonrası 4 obez hastada görülmüştür. Abdominal histerektomi yapılan $3(\% 1.9)$ hastada yara yerinde selülit gelișirken, 1 hasta dehisens nedeniyle postoperatif 4. gün yeniden opere edilmiştir. Histerektomi sonrası yara yeri infeksiyonu ile ilgili 14000 e yakın histerektomi olmuş kad1n1 içeren bir Amerika çalışmasında postoperatif selülit oranı \%1.6 olarak bildirilmiştir [16]. $\mathrm{Bu}$ çalışmada yara yeri komplikasyonları için en önemli risk faktörleri bizim çalışmamızla uyumlu olarak yüksek body mass index ve diabet olarak bildirilmiştir. Histerektomi sonrası vaginal cuff dehisensi oran $\% 0.3$ ile $\% 3.1$ arasında değișir ve abdominal ve vaginal histerektomiye kiyasla laparoskopik histerektomi sonrası daha sıktır [17-19]. Çalışmamızda vaginal cuff dehisensi önceki çalışmalarla uyumlu olarak sadece laparoskopik histerektomi grubunda $2(\% 2)$ hastada vardi. Literatürde laparotomiye dönme oranları $\% 0$ ile $\% 19$ arasında (ortalama \%3.5) değişmektedir [20]. Bir Hollanda çalışmasında 79 jinekolog tarafindan 1 yılda yapılan 1534 laparoskopik histerektomi prospektif olarak değerlendirilmiş ve laparotomiye dönme oranı \%4.6 olarak saptanmıştır [20]. Bu çalışmada en önemli konversiyon nedenleri görüş azlığ1 ve mobilite problemleriyle (\%68.6) kontrol edilemeyen kanamadır (\%14). Çalıșmamızda konversiyon oranı literatür ortalamasından yüksek olarak \%12 idi. En belirgin konversiyon nedenleri obez hastalarda respiratuar nedenlere bağlı anestezi problemleri ile adezyona ve alt segment yerleşimli leiomyoma bağlı bozulmuş anatomiydi.

Laparoskopik histerektomide operasyon süresinin abdominal histerektomiye göre daha uzun olduğu bir çok kez rapor edilmiştir [7, 8, 21]. Bizim çalışmamızda da literatürle uyumlu olarak laparoskopik histerektomi grubunda operasyon süresi daha uzundu (131 e karşı 118 dak). Ancak genel literatür bilgilerinden farklı olarak Karaman ve ark tek cerrah tarafindan yapilan laparoskopik asiste vaginal histerektomi ve laparoskopik histerektomide operasyon süresini sirasiyla ortalama 52 ve 55 dakika olarak bildirmiştir [5]. Yazarlar bu çalışmada operasyon süresinin öğrenme eğrisi ile ilişkili olarak ilk 100 vakada anlamlı olarak azaldığını, 200 vakadan sonra ise plato çizdiğini rapor etmiștir. Bizim çalıșmamızda uzun operasyon süresi ve yüksek laparotomiye dönme oranlarının nede- ni TLH grubundaki hastaların ortalama vücut kitle indeksinin obezite sınırının üstünde olmas1 olabilir (Ortalama VKİ $32 \pm 6$ ). Daha önce içinde bizim çalışmamızında bulunduğu bir çok çalışmada obezitenin uzun operasyon süresi ve artmış laparotomiye dönme oranlarıyla ilişkili olduğu rapor edilmiştir [20, 22, 23]. Laparoskopik yaklaşımın en önemli avantajlarından bir tanesi abdominal yaklaşıma göre hızlı iyileşme ve artmış yaşam kalitesidir. Toplam 59 hastanın (27 laparoskopik histerektomi, 32 abdominal histerektomi) ortalama 4 yıl izlendiği bir çalışmada laparoskopik histerektomili hastalarda abdominal histerektomiye göre daha yüksek yaşam kalitesi skorları rapor edilmiştir [24]. Johnson ve ark 27 randomize kontrollü çalışmayı değerlendirdikleri metaanalizde, laparoskopik histerektomi olanlarda normal aktiviteye dönüşün, abdominal histerektomi olanlara göre 14 gün (\%95 CI 11.8-15.4) kadar daha kısa olduğunu bildirmiştir [8]. Bizim çalışmamızda normal aktiviteye başlama zamanı ile ilgili datamız yoktu. Ancak hızlı iyileşmenin bir göstergesi olabilecek hastanede yatış süresi laparoskopik histerektomi olan hastalarda abdominal histerektomi olanlardan anlamlı olarak daha kısa saptanmıştır.

Çalışmamızda TAH ve TLH grubunda hiç bir hastamızda yeniden operasyonu gerektirecek intraperitoneal kanama görülmemiştir. Ancak postoperatif 24.saatteki hemoglobin düşüşü TAH grubunda anlamlı olarak fazla bulunmuştur.

Çalıșmamızın en önemli limitasyonları retrospektif olması ve çalıșma populasyonunun küçüklüguüdür. Ayrıca çalışmamızda belki de her parametreye etkili olan cerrahi deneyimin etkisi belirlenmemiștir. Tüm operasyonlar hastanemizin bir eğitim hastanesi olması nedeniyle deneyimli bir uzman ve bir asistan ile yapilmıştır. Daha az veya daha fazla deneyimli bir ekiple sonuçlar daha farklı olabilirdi. Bu konuda ileride yapılacak çalışmalarda cerrahi ekibin deneyimi dikkate alınmalıdır.

Biz laparoskopik histerektominin abdominal histerektomiye oranla bir çok avantaja sahip olduğunu düşünüyoruz. Deneyimli ellerde laparoskopik histerektomi güvenle uygulanabilir ve hastaların büyük bölümü için en uygun tekniktir. Çalışmamızın sonuçları laparoskopik histerektomide komplikasyon oranlarının abdominal histerektomiye kıyasla artmadığını desteklemektedir. Daha uzun operasyon süresi olsa da laparoskopik histerektomi daha az kan kaybı ve daha hızlı iyileşme ile ilişkilidir. Sonuç olarak vaginal histerektominin uygun olmadığı hastalarda laparoskopik yaklaşım ilk tercih olarak değerlendirilmelidir. 


\section{KAYNA KLAR}

1. Osler M, Daugbjerg S, Frederiksen BL, Ottesen B: Body mass and risk of complications after hysterectomy on benign indications. Hum Reprod 2011;26:1512-1518.

2. Wright JD, Herzog TJ, Tsui J, Ananth CV, Lewin SN, Lu YS, Neugut AI, Hershman DL: Nationwide trends in the performance of inpatient hysterectomy in the United States. Obstet Gynecol 2013;122:233-41.

3. Ercan Yılmaz, Çă̆atay Taşkıran, Bülent Tıraş, Haldun Güner, Onur Karabacak. Kliniğimizin 6 ylllı histerektomi tecrübesi. Turk J Obstet Gynecol 2008;5 (3):195-201.

4. Aarts JW, Nieboer TE, Johnson N, Tavender E, Garry R, Mol BW et al. Surgical approach to hysterectomy for benign gynaecological disease. Cochrane Database Syst Rev 2015;12:8:CD003677.

5. Karaman Y, Bingol B, Gunenc Z. Prevention of complications in laparoscopic hysterectomy: experience with 1120 cases performed by a single surgeon. J Minim Invasive Gynecol 2007;14:78-84.

6. Donnez O, Jadoul P, Squifflet J. A series of 3190 laparoscopic hysterectomies for benign disease from 1990 to 2006: evaluation of complications compared with vaginal and abdominal procedures. BJOG 2009;116:492500 .

7. Gary R, Fountain J, Mason S, Hawe J, Napp V, Abbot $J$ et al. The eVALuate study: two parallel randomised trials, one comparing laparoscopic with abdominal hysterectomy, the comparing laparoscopic with vaginal hysterectomy. BMJ 2004;17:328:129.

8. Johnson N, Barlow D, Lethaby A, Tavender E, Curr L, Garry R. Methods of hysterectomy: systematic review and meta-analysis of randomized controlled trials. BMJ $2005 ; 25: 330: 1478$.

9. Donnez J, Squifflet J, Jadoul P, Smets M. High rate of complications needs explanation (letter). BMJ 2004;328:643.

10. Ghosh D, Wipplinger P, Byrne L. Can total laparoscopic hysterectomy replace total abdominal hysterectomy? A 5-year prospective cohort study of a single surgeon's experience in an unselected population. Gynecol Surg 2013;10:109-15.

11. O'Hanlan KA, Dibble SL, Garnier AC, Reuland ML. Total laparoscopic hysterectomy: technique and complications of 830 cases. JSLS 2007;11:45-53.

12. Morgan-Ortiz F, Soto-Pineda JM, Lopez-Zepeda MA, Peraza-Garay Fde J. Effect of body mass index on clinical outcomes of patients undergoing total laparoscopic hysterectomy. Int J Gynaecol Obstet 2013;120:61-4.
13. O'Hanlan K, Lopez L, Dibble SL, Garnier AC, Huang GS, Leuchtenberger M. Total laparoscopic hysterectomy: body mass index and outcomes. Obstet Gynecol 2003; 102:1384-92.

14. Jelovsek JE, Chiung C, Chen G, Roberts SL, Paraiso $M F$, Falcone T. Incidence of lower urinary tract injury at the time of total laparoscopic hysterectomy. JSLS 2007;11:422-7.

15. Schindlbeck C, Klauser K, Dian D, Janni W, Friese $K$. Comparison of total laparoscopic, vaginal and abdominal hysterectomy. Arch Gynecol Obstet 2008;277:3317.

16. Lake AG, McPencow AM, Dick-Biascoechea MA, Martin DK, Erekson EA. Surgical site infection after hysterectomy. Am J Obstet Gynecol 2013;209:490.e1-9.

17. Blikkendaal MD, Twijnstra AR, Pacquee SC, Rhemrev JP, Smeets MJ, de Kroon CD et al. Vaginal cuff dehiscence in laparoscopic hysterectomy: influence of various suturing methods of the vaginal vault. Gynecol Surg 2012;9:393-400.

18. Hur HC, Donnellan N, Mansuria S, Barber RE, Guido R, Lee T. Vaginal cuff dehiscence after different modes of hysterectomy. Obstet Gynecol 2011;118:794801.

19. 20.Agdi M, Al-Ghafri $W$, Antolin R, Arrington $J$, O'Kelley $K$, Thomson AJ et al. Vaginal vault dehiscence after hysterectomy. J Minim Invasive Gynecol 2009;16:313-7.

20. Twijnstra AR, Blikkendaal MD, van Zwet EW, Jansen FW. Clinical relevance of conversion rate and its evaluation in laparoscopic hysterectomy. J Minim Invasive Gynecol 2013;20:64-72.

21. Walsh CA, Walsh SR, Tang TY, Slack M. Total abdominal hysterectomy versus total laparoscopic hysterectomy for benign disease: a meta-analysis. Eur J Obstet Gynecol Reprod Biol 2009;144:3-7.

22. Guraslan H, Senturk MB Dogan K, Guraslan B, Babaoglu B, Yasar L. Total laparoscopic hysterectomy in obese and morbidly obese women. Gynecol Obstet Invest 2015;79:184-8.

23. Martinek IE, Haldar K, Tozzi R. Laparoscopic surgery for gynaecological cancers in obese women. Maturitas 2010;65:320-4.

24. Nieboer TE, Hendriks JC, Bongers MY, Vierhout $M E$, Kluivers KB. Quality of life after laparoscopic and abdominal hysterectomy: a randomized controlled trial. Obstet Gynecol 2012;119:85-91. 